\title{
Mulheres Indígenas em Movimentos: Possíveis Articulações entre Gênero e Política ${ }^{1}$
}

\author{
Juliana Cabral de O. Dutra ${ }^{1}$ \\ Claudia Mayorga ${ }^{1}$ \\ ${ }^{1}$ Universidade Federal de Minas Gerais, MG, Brasil. \\ ${ }^{1}$ Universidade Federal de Minas Gerais, MG, Brasil.
}

Resumo: A partir de uma aproximação posicionada com determinados movimentos indígenas e com mulheres lideranças indígenas no Brasil tratamos sobre a possibilidade da emergência, no cenário macropolítico do país, do sujeito político mulheres indígenas e sobre as possíveis aproximações de suas pautas com as pautas feministas, em especial, o feminismo pós-colonial. Propomos reflexões sobre as intersecções entre raça/etnia e gênero, dialogando com discursos de diferentes lideranças indígenas que ocupam posição de protagonismo no movimento indígena e ocupam espaços políticos estratégicos como a própria Academia. Atentar-se para estas múltiplas narrativas se torna importante pois estas provocam tensionamentos múltiplos que envolvem não só campos de disputa política por direitos e visibilidade, mas também campos teóricos da antropologia e do feminismo.

Palavras-chave: Movimentos de Mulheres Indígenas, Raça/Etnia, Gênero, Feminismo, Psicologia Social.

\section{Indigenous Women in Movements: Possible Links Between Gender and Politics}

Abstract: Based on a positioned approach with indigenous movements in Brazil, we deal with the possibility of the emergence of the political subject indigenous women in the macro-political scenario of the country and the possible approximation of them with feminism, in particular, postcolonial feminism. We propose reflections on the intersections between race/ethnicity and gender, dialoguing with discourses of different indigenous leaders who occupy both a leading position in the indigenous movement and some strategic political spaces such as the Academy itself. Attention to these multiple narratives becomes important as they provoke tensions involving not only fields of political dispute for rights and visibility, but also theoretical fields of anthropology and feminism.

Keywords: Movements of Indigenous Women, Race/Ethnicity, Gender, Feminism Social Psychology.

${ }^{1}$ Agradecemos à Fundação de Amparo à Pesquisa do Estado de Minas Gerais (Fapemig) e ao Conselho Nacional de Desenvolvimento Científico e Tecnológico (CNPq) pelo apoio disponibilizado. 


\title{
Mujeres Indígenas en Movimientos: Posibles Articulaciones entre Género y Política
}

\begin{abstract}
Resumen: A partir de una aproximación posicionada con determinados movimientos indígenas y con mujeres líderes indígenas en Brasil tratamos sobre la posibilidad de la emergencia, en el escenario macropolítico del país, del sujeto político mujeres indígenas y sobre las posibles aproximaciones de sus pautas con las pautas feministas, en especial, el feminismo post-colonial. Proponemos reflexiones sobre las intersecciones entre raza/etnia y género, dialogando con discursos de diferentes líderes indígenas que ocupan posición de protagonismo en el movimiento indígena y ocupan espacios políticos estratégicos como la propia Academia. Atendiendo a estas múltiples narrativas y discursos se vuelve importante pues éstas provocan tensiones múltiples que involucran no sólo campos de disputa política por derechos y visibilidad, sino también campos teóricos de la antropología y del feminismo.
\end{abstract}

Palabras clave: Movimientos de Mujeres Indígenas, Raza/Etnia, Género, Feminismo, Psicología Social.

\section{Introdução $^{2}$}

Mesmo ciente da luta difícil que iria enfrentar tanto na cidade como em meio ao movimento indígena por ser mulher, sabendo que me encontrava numa sociedade que privilegia o domínio político masculino, eu nunca me senti intimidada. Continuamente me incentivei a iniciar minha luta ali decretando para mim mesma que iria enfrentar as dificuldades de cabeça erguida

(Nelly Duarte Marubo, 2017).

No Brasil, a participação das mulheres indígenas nos espaços públicos de discussão política em interlocução com as instituições não indígenas aumentou muito nas últimas décadas, bem como aumentou a institucionalização das organizações políticas de mulheres indígenas e o debate sobre os direitos dessas mulheres (Matos, 2012; Sacchi, 2003). Ao mesmo tempo em que são protagonistas nas discussões e reivindicações mais gerais dos povos indígenas - como a luta pela demarcação das terras - as mulheres inserem nos debates de decisões e políticas públicas temas como violência familiar e interétnica, o acesso aos meios técnicos e financeiros para a geração de renda, a saúde reprodutiva, o combate ao racismo, a soberania alimentar, a participação das mulheres nas decisões de políticas dos governos, entre outros (Voz das Mulheres Indígenas, 2018; Verdum, 2008). A partir dos diversos movimentos políticos de resistência, mulheres indígenas de diferentes etnias estão, pouco a pouco, construindo espaços de maior visibilidade política, incluindo o universo acadêmico (Xacriabá, 2018) .

Aproximar-se à realidade dos(as) indígenas, realidade tão presente na história da sociedade brasileira, mas ao mesmo tempo desconhecida e abordada de formas tantas vezes estereotipadas, exige cuidados epistemológicos, metodológicos e éticos permanentes (Mayorga, Ziller, Magalhães \& Silva, 2010). Uma reflexão crítica sobre de qual lugar perguntar sobre a realidade indígena e fazer tais perguntas de forma atenta às reproduções etnocêntricas e lógicas coloniais, devem ser preocupações permanentes no processo de pesquisa.

No caso deste estudo, as perguntas acerca das reivindicações das mulheres indígenas relacionadas à violência de gênero e outras e sua atuação e organização política se iniciaram a partir de uma experiência profissional no período de 2015 a 2017 quando atuei em uma organização indigenista não

\footnotetext{
${ }^{2}$ Este artigo é parte de pesquisa de mestrado realizada por Juliana Dutra, primeira autora deste trabalho, sob orientação de Claudia Mayorga. O texto está escrito utilizando primeira pessoa do plural e singular, no segundo caso, por apresentar reflexões diretamente relacionadas a experiências vividas por Juliana Dutra.

${ }^{3}$ Célia Xakriabá é professora e ativista indígena do povo Xakriabá, mestre em educação pela UnB. Foi a primeira indígena que atuou como parte da equipe da Secretaria de Estado de Educação de Minas Gerais.
} 
governamental junto a povos indígenas Carib do norte do Pará (municípios de Oriximiná, Nhamundá, Faro e Urucará), em um projeto em parceria com a Fundação Nacional do Índio (Funai) voltado para política de proteção de povos isolados. Durante minha atuação, pude acompanhar organizações e movimentos então incipientes de mulheres indígenas da região, como a Associação de Mulheres Indígenas da Região de Oriximiná (AMIRMO) e a Assembleia de Mulheres no Rio Cachorro, quando as questões de gênero entre povos indígenas e a diversidade de realidades e narrativas relacionadas a violência contra a mulher indígena e suas estratégias de enfrentamento me chamaram a atenção.

Nessa mesma época, trabalhei com certa proximidade a Ângela Amanakwa Kaxuyana, uma mulher jovem liderança Katxuyana - povo que habita o Rio Cachorro, afluente do Rio Trombetas. Nesse encontro pude observar que essa jovem mulher cumpriu uma trajetória de vida diferente da maioria das mulheres indígenas daquela região: foi estudar na capital do estado, Belém, onde concluiu a graduação e se conectou com o movimento indígena regional e nacional. Os postos de liderança mais comuns atualmente entre os povos indígenas Carib da porção oeste da região norte do Pará (que habitam os rios Jatapu, Nhamundá, Cachorro, Trombetas e Mapuera) - são ocupados por lideranças masculinas - caciques, pastores, presidentes de associações, conselheiros de saúde, professores etc., cabendo às mulheres um papel político forte, mas nem sempre visível diante da perspectiva de não indígenas (Rodrigues, 2015). Observei, naquele período, que entre estes povos, a ligação com as organizações indígenas de âmbito regional e nacional como a Coordenação das Organizações Indígenas da Amazônia Brasileira (Coiab) e a Articulação de Povos Indígenas do Brasil (APIB) era geralmente pontual e pouco a pouco se tornava mais intensa.

Em contraponto, foi possível identificar que Ângela exercia na região e começava a exercer nacionalmente um papel de liderança diferenciado e legitimado pelo seu povo. Na ocasião ela atuava como assessora técnica da Associação Indígena Kaxuyana, Tunayana e Kahyana (AIKATUK) e era protagonista na luta pela demarcação da Terra Indígena Kaxuyana Tunayana. Naquele período, foi membro fundadora e secretária da Federação dos Povos Indígenas do Estado do Pará (Fepipa), se tornou membro do conselho nacional de política para povos isolados e recente contato, representante no Conselho Nacional de Saúde onde é membro do Comitê Intersetorial de Mulheres e participante do projeto Voz das Mulheres Indígenas implementado pela Organização das Nações Unidas (ONU) ${ }^{4}$.

Durante o meu trabalho naquela região, pude observar a atuação de Ângela voltada para a organização de mulheres indígenas. Interessada pelo tema, solicitei à liderança que autorizasse minha participação na 2aAssembleia de Mulheres Indígenas da Região de Oriximiná, que foi realizada na aldeia Santidade, no Rio Cachorro em maio de 2016, e envolveu mulheres de diferentes idades dos rios Cachorro, Nhamundá e Mapuera. Ao participar deste encontro, compreendi que o mesmo teve origem na primeira Assembleia, também organizada por Ângela (representando a AIKATUK), realizada em fevereiro de 2015 na aldeia Chapeu (Rio Cachorro). Segundo a liderança, já teria sido possível observar resultados positivos do primeiro encontro como, por exemplo, uma inesperada participação ativa das mulheres na etapa local do CNPI (Conselho Nacional de Política Indigenista) $-80 \%$ dos delegados elegidos para as etapas regionais eram mulheres. Nesta segunda Assembleia, cuja principal pauta foi a saúde das mulheres, e contou com presença de enfermeiras que representavam a Secretaria Especial de Saúde Indígena (Sesai), ficou evidente para todos os presentes que muitas das reivindicações levantadas pelas mulheres nunca haviam sido apresentadas ou discutidas em outras assembleias.

Além de apresentarem demandas mais gerais em relação ao serviço de saúde que já são recorrentes em outros espaços de discussão - como falta de postos de saúde, contratação de Agente Indígena de Saúde e fornecimento de medicamento suficiente nas aldeias - pela primeira vez foram apresentadas questões específicas relacionadas à saúde da mulher indígena como a falta de maca ginecológica, falta de estrutura adequada para realização de exames ginecológicos nas aldeias e salubridade das salas de acolhimento às mulheres no puerpério na Casa de Saúde Indígena (Casai) da cidade.

A questão do parto na cidade foi o que me chamou mais atenção. As mulheres declararam que não

\footnotetext{
${ }^{4}$ A partir de agosto de 2017, Ângela passou a ser Coordenadora Tesoureira da COIAB.
} 
estavam satisfeitas em serem induzidas a parir na cidade, pois no hospital, os médicos não permitem que elas entrem acompanhadas e não autorizam que o parto seja realizado conforme seus costumes. Elas ainda denunciaram que nos hospitais corta-se e joga fora, sem autorização das mães, o cordão umbilical, o que não é uma prática desejável para este povo, pois não é compatível com seus rituais e cosmologia. Diante da argumentação da representante da Sesai que explicou que a política daquele Distrito Sanitário Especial Indígena (DSEI) é o de encaminhar todas as mulheres para a cidade de Oriximiná no oitavo mês de gestação, mesmo quando corre tudo bem na gestação, pois as aldeias não têm nenhuma estrutura para socorrer as parturientes no caso de haver alguma intercorrência - as mulheres disseram que se sentem coagidas a aceitar o encaminhamento, pois sabem que se não o fizerem poderão ser culpabilizadas, tanto pelos maridos quanto pelos funcionários da saúde, caso algum imprevisto venha a ocorrer. Foi interessante observar que a enfermeira responsável que já atuava nos rios Cachorro e Trombetas há mais de um ano e apresentava uma relação próxima com os(as) indígenas, falando inclusive sua língua, afirmou que nunca tinha tido acesso a essas reivindicações. Ela admitiu sua surpresa diante desta insatisfação das mulheres, e afirmou que, de fato, acreditava que elas estavam satisfeitas em parir na cidade.

Ao participar de espaços como esta Assembleia no rio Cachorro e de eventos como o Acampamento Terra Livre em 2016 e 2018, fui aprendendo que a violência e o machismo que atingem as mulheres indígenas e as especificidades das desigualdades de gênero vivenciadas por elas, no que diz respeito ao acesso as políticas públicas de saúde, por exemplo, são muito diversos e percebidos de formas diferentes e até divergentes daqueles nomeados pelos movimentos de mulheres de outros contextos e raça/etnias. Contudo, ficou evidente também que a reivindicação pelo protagonismo e pelo reconhecimento e visibilidade de suas experiências é um aspecto compartilhado pelos outros movimentos de mulheres.

Foi a partir dessa aproximação que pude elaborar uma proposta de pesquisa que está sendo desenvolvida desde 2018 no âmbito do programa de Pós-graduação em Psicologia da UFMG. Com essa pesquisa, pretendo contribuir com estudos e intervenções que, com base em referenciais psicossociológicos e psicopolíticos, colaborem na compreensão da desigualdade social brasileira em suas diversas faces, incluindo a desigualdade de gênero, bem como dos processos participativos na democratização das sociedades e na dinamização da esfera pública.

\section{Anotações metodológicas: interagir para conhecer}

Nesta seção, exponho e reflito acerca da inserção no campo (Spink, 2003), primeira fase da pesquisa de mestrado, na qual se baseiam as discussões apresentadas na seção seguinte. Nesse sentido, meu contato com povos indígenas em distintas regiões do país (Minas Gerais e Pará) se deu mediada por outras instituições (Ministério Público Federal de Minas Gerais e Funai), a partir da perspectiva da pesquisa participante (Montero, 2004; Borda, 2009), associada a uma revisão de literatura com foco nas produções de intelectuais indígenas vinculados(as) ou não à academia (Patai, 2010; Castro, \& Mayorga, 2018).

Quando já estava inserida no programa de pós-graduação, a Pró-reitoria de Extensão da UFMG recebeu uma demanda do Ministério Público Federal de Minas Gerais (MPF-MG) que estava dando encaminhamento a algumas reivindicações do povo Kaxixó, incluindo uma demanda do grupo Mulheres Guerreiras Kaxixó relacionada à saúde mental e ao atendimento psicológico de qualidade na aldeia.

Para início dos trabalhos e para uma primeira aproximação e escuta, um grupo de professora e estudantes dos cursos de graduação e pós-graduação em Psicologia da UFMG, em conjunto com o MPF, realizou, no final de 2017, visita à aldeia Kaxixó, Capão do Zezinho, localizada no município de Martinho Campos (MG). No primeiro semestre de 2018, foram realizados visitas e encontros, quando foi discutida a proposta de pesquisa com o grupo Mulheres Guerreiras. Nesses encontros foi possível conhecer mais acerca da aldeia, escutar parte da história do povo Kaxixó e conversar com mulheres da comunidade que apresentaram novamente a demanda antes direcionada ao MPF. As mulheres nos contaram um pouco sobre o grupo criado por elas, Mulheres Guerreiras, sobre suas experiências, sobre as potencialidades coletivas de combate ao sofrimento e sobre as aproximações anteriores que já haviam tido com a Psicologia, as quais foram marcadas por encontros positivos e negativos. $\mathrm{O}$ uso indiscriminado de medicamentos psicotrópicos foi apontado por elas como um problema grave. Segundo o Plano de Gestão Territorial 
e Ambiental da Terra Indígena Caxixó, há na comunidade um compartilhamento e/ou indicação de remédios sem orientação médica, além da automedicação (Cedefes, 2016).

No contexto destas aproximações, uma das lideranças Kaxixó que tivemos a oportunidade de conhecer, Liderjane Gomes da Mata, publicou o texto "Memória do sagrado enquanto resistência ao medo" no livro "Povos indígenas e Psicologia" publicado pelo Conselho Regional de Psicologia de São Paulo CRP-SP (2016). Nessa publicação, Liderjane fez apontamentos que se repetiram durante a conversa realizada em 2017:

Viemos sofrendo muito abuso, tanto de expulsar nossos antepassados da terra, como também estupraram nossos parentes e antepassados. Com isso, veio surgindo um medo muito grande. Uma fobia de tudo. Não só do fazendeiro como do homem branco. [...] Tem muita depressão, ansiedade dentro da comunidade. Não só na minha, como várias outras etnias que, se não é pelo fazendeiro, genocídio, é pela igreja que tem medo de tudo (Mata, 2016, p. 79).

Assim como outros povos indígenas do país, a história do povo Kaxixó é marcada por muitas violências e conflitos territoriais. Atualmente, as 29 famílias que vivem no território Kaxixó ocupam apenas 15 hectares dos 5.411 hectares identificados e delimitados pela Funai ${ }^{5}$. Confinada neste pequeno território, esta população sofre constantemente pressão do agronegócio e da especulação imobiliária ${ }^{6}$. Entretanto, os relatos de violência, ameaças, tentativas de expulsão, exploração da mão de obra, discriminação, racismo, dentre outras denúncias, não marcam apenas a atualidade. Estas relações desiguais fazem parte da história deste povo desde o início da ocupação não indígena na região - quando, no século XVIII, uma família de europeus e seus descendentes foram para a região levando um grande contingente de indígenas e de negros escravizados (Caldeira 2001; 2006; 2008; Oliveira 2003; Santos, 2003).
Desde que emergiram como grupo étnico indígena politicamente organizado, na década de 1980, os Kaxixó sofrem constantes contestações, inclusive jurídicas, em relação a sua identidade étnica e, consequentemente, ao seu direito de ocupação do território tradicional. Neste sentido, é comumente utilizado o argumento que frequentemente aciona uma imagem de um "índio" imaginário para negar a legitimidade da autoidentificação do povo Kaxixó. Altair, o atual vice-cacique do povo Kaxixó afirma em entrevista:

Eles falam que não existia índio, existia sim. Só que aí foi perdendo a língua, foi perdendo a origem, né?! Como é que você vai ter a sua origem pura se você foi domesticado, as índias foram estupradas... Muita gente ainda fala "mas como é que você é índio se você é branco?" Mas eu falo, "mas como é que você quer que eu seja moreno se foi vocês mesmo que misturou minha raça?" (Altair Kaxixó, 2017).

Apesar da nítida participação direta e ativa das mulheres Kaxixó na luta pelo reconhecimento étnico, pela demarcação da terra, na organização política e social comunitária, no trabalho da saúde e da educação, suas narrativas e perspectivas foram invizibilizadas nos laudos oficiais e textos acadêmicos produzidos sobre este grupo. As formas específicas de violências perpetradas contra as mulheres Kaxixó durante todo esse processo histórico de colonização, escravização e estabelecimento de relações de dominação também não foram muito explicitadas e denunciadas, se tornando assunto não dito dentro da própria aldeia. No que diz respeito a visibilidade, Mariceia Meirelles Guedes Pataxó (2017), liderança Pataxó de Aldeia Velha, afirma:

As mulheres indígenas estão presentes em tudo. Às vezes, não tem muita visibilidade, né. Às vezes, a luta das nossas mulheres não tem essa visibilidade que deveria ter. Porque essa opressão já surge dentro das nossas comunidades. Porque nós somos mulheres, nós temos filhos, nós temos

\footnotetext{
${ }^{5}$ O Relatório Circunstanciado de Identificação e Delimitação da Terra Indígena Caxixó foi publicado em 2013, mas o processo de demarcação da Terra indígena se encontra paralisado devido a uma ação judicial perpetrada pelas prefeituras de Matinho Campos e Pompéu em conjunto com fazendeiros locais (Cedefes, 2016).

${ }^{6}$ As principais ameaças apontadas atualmente pelos Kaxixó envolvem a monocultura de eucalipto, contaminação por agrotóxico, captação de água do rio Pará para irrigação com pivô central, loteamento irregular às margens do rio, pesca predatória, desmatamento, pesquisa e exploração mineral (Cedefes, 2016).
} 
maridos e nós não podemos sair, nós temos que ficar em casa e a maioria das pessoas que são escolhidas são os homens.

Com essas questões em mente, no final de 2018, iniciei inserção no município de Altamira, no estado do Pará, junto aos povos indígenas da região devido a atuação profissional na Fundação Nacional do Índio (FUNAI). Já na primeira oportunidade que tive de ir a campo visitar aldeias dos povos Assurini, Araweté e Parakanã (sendo estes dois últimos considerados povos de recente contato), no médio Rio Xingu, me surgiram mais centralmente, questionamentos relacionados ao problema da representatividade e à questão da diversidade. É possível identificar um movimento de mulheres indígenas, considerando contextos tão diversificados?

Em torno de um mesmo rio, em cada uma das três terras indígenas que visitei, encontrei realidades distintas uma das outras, com histórias completamente diferentes das do povo Kaxixó, de Minas Gerais. Ao visitar 18 aldeias desses três povos, identifiquei que a maioria dessas mulheres de povos diferentes, que inclusive parecem pouco dialogar entre si, são marcados por uma grande diversidade. Em cada uma dessas terras do Médio Xingu, se fala uma língua distinta e poucas mulheres dominam o português.

Mesmo diante do questionamento da possibilidade de um movimento nacional de mulheres que seja representativo de realidades e contextos tão plurais, permanecia a pergunta: Como as mulheres indígenas, imersas em contextos de macropolítica interétnica, narram questões vinculadas à violência de gênero e quais suas estratégias políticas de enfrentamentos aos ataques que historicamente mulheres indígenas sofreram, sofrem e tem pautado? Como essas mulheres e suas organizações têm se organizado e reivindicado e o que têm produzido coletivamente?

A partir dessas distintas interações, pude compreender que os discursos e narrativas dessas mulheres indígenas e seus coletivos que, cada vez se inserem com mais força, tanto no âmbito macropolítico quanto acadêmico, são vozes importantes que tem tensionado os campos de disputa pautando políticas públicas e propondo novos olhares e novas articulações entre diferentes atores sociais.

A minha aproximação com a diversidade de mulheres indígenas tem colocado, como mencionado anteriormente, questões metodológicas bem práticas como a diversidade de línguas. Para pensar na possibilidade deste encontro com saberes indígenas é necessário, ainda, atentar para o reconhecimento de outras formas de transmissão de conhecimento, além da linguagem escrita tendo em vista que, entre os indígenas, esta se dá tradicionalmente pela oralidade. Segundo o xamã yanomami Davi Kopenawa:

Os brancos se dizem inteligentes. Não o somos menos. Nossos pensamentos se expandem em todas as direções e nossas palavras são antigas e muitas. Elas vêm de nossos antepassados. Porém, não precisamos, como os brancos, de peles de imagens para impedi-las de fugir da nossa mente. Não temos de desenhá-las, como eles fazem com as suas. Nem por isso elas irão desaparecer, pois ficam gravadas dentro de nós. Por isso nossa memória é longa e forte. (Kopenawa, 2015, p. 75)

Partindo do pressuposto de que não há verdade absoluta na construção de um problema científico, tomo como base Donna Haraway (1995, p. 33) para quem "o único modo de encontrar uma visão mais ampla é estando em algum lugar em particular". Segundo a autora, há uma ideologia de objetividade universal que em pouco se difere do relativismo: ambos prometem igualmente e inteiramente, visões de toda parte e de lugar nenhum, "mitos comuns na retórica em torno da Ciência" (Haraway, 1995, p. 24). Em contraposição, a autora argumenta a favor de uma epistemologia feminista onde a universalidade deixa sua centralidade, dando lugar a parcialidade como condição para um "fazer de conhecimento racional", não tratando, dessa forma, da "divisão entre sujeito e objeto". "Desse modo podemos nos tornar responsáveis pelo que aprendemos a ver (Haraway, 1995, p. 30)".

A autora alerta, entretanto, para o "sério perigo em se romantizar e/ou apropriar da visão dos menos poderosos ao mesmo tempo que se alega ver desde a sua posição". Assim, "ver desde baixo" necessitaria de "tanta habilidade com corpos e linguagens, com as mediações da visão, quanto têm as mais 'altas' visualizações tecnocientíficas". A alternativa apontada são "os saberes parciais localizáveis, críticos, apoiados na possibilidade de redes de conexão, chamadas de solidariedade em política e de conversas compartilhadas em epistemologia" (Haraway, 1995, p. 23). É neste sentido que temos pretendido construir uma pesquisa não sobre, mas com mulheres indígenas. 
Dessas distintas interações, das revisões de literatura, sobretudo aquelas de autoria indígena, destacamos dois pontos que nos ajudam a responder sobre a possibilidade da emergência, no cenário macropolítico do país, do sujeito político mulheres indígenas e sobre a possível relação de suas pautas com as pautas feministas e relacionadas às questões de gênero. Refletiremos sobre as intersecções entre raça/etnia e gênero e sobre as pautas que tem sido apresentadas pelos movimentos de mulheres indígenas e por mulheres que ocupam posição de protagonismo no movimento indígena.

\section{Resultados e discussões}

\section{Intersecções entre raça/etnia e gênero}

Para responder às questões levantadas, é necessário considerar algumas reflexões acerca da categoria "mulheres indígenas" e sobre as interseções entre dois diferentes marcadores sociais: raça/etnia e gênero. É importante compreender que o uso do termo "indígena", originado do latim, para designar populações autóctones de um país ou que neste se estabeleceu anteriormente a um processo colonizador, é um discurso ocidental que sugere uma pretensa e simplificada unidade identitária que abrange povos extremamente diversos, falantes de diferentes línguas, localizados em variados territórios e, muitas vezes, antagônicos. Segundo o antropólogo indígena baniwa, Gersem Luciano (2006), desde a chegada dos europeus, os habitantes nativos foram alvo de diferentes percepções e julgamentos quanto às características, aos comportamentos, às capacidades e à natureza biológica e espiritual que lhes são próprias.

Neste cenário, Baniwa (Luciano, 2006) aponta duas perspectivas sociais estigmatizantes sobre o índio forjadas desde a chegada dos colonizadores no Brasil. A primeira se refere ao índio romantizado, ligado a ideia do bom-selvagem, de um ser idílico, puro, ingênuo, protetor da natureza, índio manso, atribuído de valores europeus, cuja imagem foi apropriada para construção de uma identidade nacional durante o movimento literário modernista e durante o romantismo e, por fim, necessitado de tutela para ser "assimilado" e "integrado" à sociedade moderna. A segunda imagem se refere ao índio selvagem, bravo, cruel, bárbaro, canibal, preguiçoso, animalizado, dentre outros adjetivos pejorativos. Esta visão é historica- mente acionada para tratar do indígena quando este é percebido como entrave aos interesses econômicos e desenvolvimentistas, e para justificar seu extermínio quando há interesse nas terras indígenas e em seus recursos naturais.

Além disso, a partir do reconhecimento dos direitos dos povos indígenas, surgem os discursos que negam a "indianidade" daqueles sujeitos e grupos que se identificam como pertencentes a um grupo étnico mas não correspondem a estas imagens reducionistas e historicamente construídas; possuem pele clara, utilizam aparelhos tecnológicos modernos ou não são mais falantes da língua nativa, por exemplo. Constrói-se assim uma significação racista e opressora sobre o ser indígena que é trazido para o campo do "legível" a partir de uma perspectiva estereotipada, preconceituosa, pictórica e reduzida que reitera a desumanização e deslegitima esses grupos e contribui para o aumento da exposição a violência, criminalização e condição de vulnerabilidade destes sujeitos. Estas existências (plurais) permanecem, então, não reconhecidas. Esta visão estereotipada sobre o que é o índio ou o que deveriam ser as comunidades indígenas é construída desde o início da colonização e serve, também institucionalmente, para negar o devido reconhecimento étnico aos indígenas e logo os direitos assegurados aos povos originários (Figueiredo, 2016).

A autoidentificação enquanto "indígenas" ou "índios", por parte de diferentes sujeitos e grupos nativos, é contingente, atribuída de diferentes significados e começa a se dar a partir das primeiras relações de contato com o colonizador que ainda seguem acontecendo. Esta identidade coletiva é marcada pela delimitação de uma fronteira política comum que marca a diferenciação entre um "nós" e um "eles" levando a um processo constante de reciprocidade, reconhecimento e articulações políticas (mesmo que tensas) entre estes grupos. A demarcação de fronteiras implica no fato de que "eles" e nós" são irreconciliáveis. Assim, o "nós" se vê impelido a definir um consenso grupal que é, entretanto, precário e provisório (Mayorga, \& Prado, 2010).

Os próprios indígenas também se inserem neste campo onde diferentes atores disputam pela legitimação de uma imagem de "índio" que sirva como melhor argumento aos diferentes interesses e perspectivas (Arruda, 2001). No espaço sociocultural ampliado, constituído pela situação de contato, as 
sociedades indígenas reinterpretam-se e reconstroem sua auto-imagem como sujeitos coletivos definidos por suas tradições (Arruda, 1994). Gersem Baniwa (Luciano, 2016) descreve como a partir da década de 1970 se consolidaram, de forma mais institucionalizada e a nível nacional, movimentos indígenas politicamente organizados que passaram a propor a construção de uma terceira perspectiva social que concebesse os índios como sujeitos de direitos e, portanto, de cidadania ${ }^{7}$, como garante, em teoria, a constituição federal de 1988 (Luciano, 2006). Os indígenas passaram, então, a participar deste campo sociopolítico de disputa, instituindo-se como sujeitos desse processo de significação, buscando legitimar uma identidade diferenciada (Arruda, 1994) ${ }^{8}$.

Se por um lado, a autoidentificação enquanto indígenas inclui em uma só categoria uma diversidade incalculável de povos, etnias e existências que por sua vez camuflam infinitas possibilidades de sentidos e cosmogonias inapreensíveis pelas nossas lentes, ela também evidencia identificações em seus modos de vida e práticas culturais e é composta por grupos que, no âmbito dos discursos macropolíticos, se posicionam explicitamente, em sua maioria, como sujeitos a forças comuns de dominação coloniais sócio-políticas e econômicas, e às quais articulam estratégias de enfrentamento.

No caso das mulheres indígenas, podemos afirmar que esta identidade política é composta por indígenas que também estão marcadas por forças de dominação de gênero? Mariceia Guedes Patoxpo afirma que as mulheres indígenas além de sofrerem a estigmatização étnica e racial, são marcadas pela desigualdade de gênero: "[...] falando das mulheres, nós sofremos duplamente o olhar preconceituoso. Primeiro por ser mulher, segundo por ser indígena" (Guedes, 2017). Estas interseções de categorias de opressão em relação às mulheres indígenas se produzem de formas específicas e ainda se dá pouca atenção para o tema no âmbito acadêmico. Em "Sexo y la Norma", a antropóloga argentina Rita Segato (2014) aponta, a partir de suas experiências em contato com mulheres indígenas no Brasil, uma lista de diferentes agressões sofridas por mulheres indígenas que crescem à medida que avança o que ela chama de "frente estatal-empresarial-midiático-cristã". A partir de outra perspectiva, a filósofa argentina Maria Lugones $(2007 ; 2014)$ afirma que a modernidade colonial é totalmente marcada pelo que ela chama de sistema moderno colonial de gênero, o qual permeia todos os aspectos da existência social e dá origem a novas identidades sociais e geoculturais.

É possível que estes denominadores comuns e as experiências compartilhadas contribuam para gerar sentimentos de solidariedade entre mulheres de diferentes grupos étnicos, que se organizam em movimentos políticos e lutam por reconhecimento, direitos e justiça social. Trata-se então de entender mulher indígena e indígena, enquanto categorias cujos significados estão em disputa, buscando entender quais ressignificações operam no âmbito da resistência.

É importante enfatizar, entretanto, que a articulação de certas categorias sociais não ocorre de forma linear e harmônica, e, por isso, a abordagem interseccional proposta por perpectivas feministas, exige cuidados analíticos e políticos ${ }^{9}$. Para Mayorga, Coura, Miralles e Cunha (2013, p. 465), a compreensão histórica e política das relações entre posições de desigualdade vivenciadas por e entre mulheres é imprescindível para que esta proposta de articulação entre os diferentes marcadores sociais não se transforme em apenas uma simples e ingênua somatória de opressões. Ro'otsitsina Juruna (Xavante, 2017) nos faz refletir sobre a complexidade da articulação entre gênero e povos indígenas quando diz: "Nós, como mulheres indígenas não somos parte de um povo, nós somos o povo". Aqui vale apontar que, em geral, no âmbito dos movimentos de mulheres indígenas, a pauta pela demarcação das terras segue sendo prioritária, assim como o é para o movimento indígena como um todo. Ao ser questionada sobre o projeto $\mathrm{Voz}$ das Mulheres Indígenas, Sônia Guajajara afirma:

E surpreendentemente, o que que é que a gente traz como prioridade? Enquanto mulher?

\footnotetext{
${ }^{7}$ Para negar a colonização e estabelecer o diálogo, as sociedades indígenas tiveram que aprender a lógica do colonizador, remodelando-se e politizando-se enquanto indígena. São, então, obrigados a utilizar conjuntos simbólicos, políticos e ideológicos produzidos pelos não indígenas já que suas noções não são compreendidas ou consideradas no âmbito do sistema amplo que as incorpora (Arruda, 2001). ${ }^{8}$ Isso não significa, entretanto, que, mesmo com o marco constitucional e com a mudança da política indigenista, os processos socioeconômicos e políticos anti-indígenas, de viés assimilacionista e integracionista, não continuam predominantes (Arruda, 1994).

${ }^{9} \mathrm{O}$ termo interseccionalidade foi desenvolvido por Crenshaw (2004), entretanto, outras autoras de feminismos pós-coloniais como Audre Lorde, Cheryl Clarke Barbara Smith, entre outras já vinham trabalhando com a ideia de pensar a articulação entre diferentes categorias de opressão (Curiel, 2007).
} 
A garantia do território. Então a pauta nossa pelo território é uma pauta comum para mulheres e homens. Então é só garantindo o território é que a gente consegue se manter enquanto povo, enquanto indígena. Se a gente não tem território, daí não tem a saúde, não tem a educação. Não tem nada mais né. Então é preciso que a gente continue junto nessa luta pelo território. E aí é claro, paralelo a isso, vem todas essas discussões e essas pautas que também são urgentes, que são esses direitos às especificidades das mulheres (2018).

Mayorga e Prado (2010) compreendem que as articulações entre as categorizações sociais além de estarem vinculadas ao contexto hegemônico em que estão inseridos os atores sociais e os adversários, dependem da própria capacidade dos atores de colocarem em pauta a contingência histórica das formas de subordinação.

Além das categorias de raça/etnia e gênero, compreender os movimentos políticos de mulheres indígenas tem exigido reflexões mais aprofundadas em torno das noções de branquitude e colonialidade enquanto ideias que se inter-relacionam. A noção de colonialidade do poder, proposta pelo sociólogo Peruano Quijano (2000), denuncia um padrão de relação de dominação produzido e pelas estruturas do sistema capitalista moderno que marcou o colonialismo, mas que não findou com o término das relações entre colônia e império e que não se restringe a relações políticas e administrativas. Segundo Lugones (2014, p. 939), a noção de colonialidade proposta por Quijano refere-se à "classificação das populações do mundo em termos de raças - a racialização das relações entre colonizadores e colonizados/as", "a um novo sistema de controle da autoridade coletiva em torno da hegemonia do Estado-nação que exclui as populações racializadas como inferiores do controle da autoridade coletiva".

Se o racialismo é, portanto, a classificação social da população conforme suas características fenotípicas que dão base ao conceito de raça, constituído segundo uma perspectiva eurocêntrica com o objetivo de criar uma classificação social que justifique o padrão de dominação próprio da Colonialidade do Poder, entende-se, então, os povos originários da América enquanto grupos que foram e são racializados (Gonçalves, 2015).
Grosfoguel (2016) aponta a invasão das Américas no século XVI como um dos quatro genocídios/ epistemicídios que fundaram as estruturas "modernas, coloniais, capitalistas e patriarcais" de poder. $\mathrm{O}$ autor relembra que no processo de colonização das Américas, foi questionado se os povos indígenas possuíam ou não religião, durante um famoso julgamento em 1552, em Valladolid na Espanha. Para o autor, no imaginário cristão do século XVI, não ter uma religião equivalia a não ter uma alma, isto é, ser expulso da esfera do humano. "Mas questionar se os 'índios' possuíam ou não almas já era uma questão racista com referência direta à humanidade" (Grosfoguel, 2016, p. 17).

Enfatiza-se, então, que o processo de racialização que sofreram os povos indígenas é diferente daquele vivido pelos negros. O Estado produziu mecanismos de controle cultural e social diferentes para cada um desses recortes, sendo necessário compreender e nomear as especificidades da configuração da racialização e do racismo que sofrem os indígenas para que se possa combatê-lo.

Sobre a dupla categoria raça/etnia, Kércia Figueiredo (2016, p. 7) aponta:

apesar dos estudos sociológicos ou antropológicos recortarem com bordas tão precisas os estudos de raça ou etnia, na prática raça e etnia estão imbricadas na sociedade. Essa imbricação é percebida plenamente quando se trata do racismo que atinge sejam índios ou negros. Que tanto raça quanto etnia sejam construções sociais, esmiuçadas por inúmeros estudiosos de vários campos, não há dúvida. Resta compreender o porquê de raça ter sido ligada à aparência, e de etnia à essência.

Portanto, assim como a ideia de raça, a atribuição de etnicidade também está ligada à ideia de classificação hierárquica da humanidade, embora seja menos associada ao fenótipo e a aparência, como o é a raça, e mais associada a cultura. Sobre etnicidade, Agier aponta:

A priori, a noção de etnicidade não apresenta nenhum conteúdo em si, é um significante disponível, receptáculo apenas definível negativamente: ela designa um universo de práticas, instituições e representações, que não é aquele das classes sociais, nem o das raças, nem somente $o$ 
universo da cultura. Sendo assim, a formação da sua substância própria remete logo aos universos conexos do racismo, da cultura, da organização social (Agier, 1991, p. 2).

Entretanto, se historicamente os debates sobre raça e racismo passaram a ser automaticamente associados aos negros e vice-versa, o mesmo aconteceu em relação aos indígenas em relação a ideia de etnicidade e cultura, o que os afastou dos debates sobre racismo, entre outras desigualdades sociais que marcam suas experiências, e contribuiu para a invisibilização de seus movimentos de resistência (Figueiredo, 2016).

No Brasil, Maria Aparecida Silva Bento (2007) aprofunda a abordagem do racismo enquanto sistema que gera formação de identidade racial, e no caso da identidade branca, enquanto um processo ideológico. Segundo a autora, este sistema gera um legado cumulativo para negros e brancos que não é apenas de déficits e privilégios econômicos, políticos e sociais. Essa herança comporta igualmente uma visão de mundo, um legado subjetivo que é diferente para brancos e negros. Branquitude é, portanto, uma posição de poder, de onde o sujeito branco vê os outros e a si mesmo. É um lugar confortável do qual se pode atribuir ao outro aquilo que não se atribui a si mesmo: a raça (Schucman, Costa, \& Cardoso, 2012).

Assim, apesar dos estudos críticos sobre branquitude serem historicamente propostos para se pensar no lugar de vantagem estrutural dos(as) brancos(as) em relação em aos(às) negros(as) (López, 2015), é fundamental propor, neste contexto, que se pense em branquitude também enquanto um lugar de privilégio dos(as) brancos(as) em relação aos(às) indígenas ${ }^{10}$. Cito novamente Kopenawa quando afirma: "Os brancos se dizem inteligentes” (Kopenawa, \&Albert, 2015, p. 75).

\section{Mulheres Indígenas em Movimentos}

As duas primeiras organizações brasileiras exclusivas de mulheres indígenas surgiram na década de
1980. As pioneiras foram a Associação de Mulheres Indígenas do Alto Rio Negro (AMARN) e a Associação de Mulheres Indígenas do Distrito de Taracuá, Rio Uaupés e Tiguié (AMITRUT). As demais organizações de mulheres indígenas ou departamentos de mulheres dentro de organizações indígenas foram se constituindo a partir da década de 1990, criando-se em 2002, na ocasião de um primeiro encontro de mulheres indígenas amazônicas, um Departamento de Mulheres Indígenas dentro da Coordenação das Organizações Indígenas da Amazônia Brasileira Coiab. Deste, surgiu a União de Mulheres Indígenas da Amazônia Brasileira (UMIAB) em 2009 (Sacchi, 2003; Verdum, 2008).

Com a institucionalização das demandas das mulheres indígenas, lideranças indígenas femininas passaram a frequentar, cada vez mais, reuniões nacionais e internacionais, o que propiciou a consolidação e a articulação de suas organizações. Segundo Verdum (20018), o processo vem ainda fortalecendo a capacidade de determinadas organizações de mulheres indígenas para participar e exercer o controle social na esfera pública em interlocução com a sociedade não indígena.

Valéria Paye Kaxuyana e Suzy Silva ${ }^{11}$ (2008, p. 38) faz, entretanto, uma importante ressalva com relação a variedade no grau de discussão entre cada organização, às diferentes esferas que os diferentes movimentos alcançam, as disparidades na organização destes movimentos e a ideia problemática de representatividade:

As disparidades na organização desse movimento de mulheres indígenas se dão por uma variedade de motivos que vão desde os geográficos aos étnicos, o que é peculiar quando se trata de povos indígenas. Não há representatividade indígena nacional. O que se tem são representações regionais que discutem em nome de sua região, do seu povo, do coletivo. Assim como é prática, em reuniões de cunho oficial, que seus participantes levem as propostas apresentadas para serem

\footnotetext{
${ }^{10} \mathrm{~A}$ assimetria racial/colonial e de classe, no contexto desta pesquisa com mulheres indígenas, sendo eu uma mulher branca de classe média de Belo Horizonte está dada e certamente influencia o processo investigativo, não devendo ser camuflada no processo de escrita, caso contrário, incorre-se ao equívoco de estar propondo uma suposta produção científica neutra, isenta destes marcadores sociais de opressão. Não desconheço que enquanto pessoa latino-americana sou racializada e considerada mulher de cor em contextos internacionais, mas aqui levo em consideração o racismo que se configura no Brasil, onde o fenótipo se dá como fronteira da branquitude (Schucman, Costa, \& Cardoso, 2012).

${ }^{11}$ Valéria Paye, indígena Kaxuyana e Tiriyó, é graduada em Ciências Sociais pela UnB, foi membro do Departamento de Mulheres, Infância e Juventude Indígena Coiab, e chefe de serviço na Coordenação de Gênero e Geracional (Coger) da Funai. Foi uma das responsáveis pela formação da APIB.
} 
discutidas e decididas nas suas bases, o mesmo também ocorre com as mulheres indígenas.

Como também pude notar no Pará, nos últimos anos, muitas organizações de mulheres indígenas em todo o Brasil têm sido também fortemente fortalecidas e estão em constante diálogo com instituições não indígenas governamentais e não governamentais (Sacchi, 2003). Destaca-se o projeto Voz das Mulheres Indígenas, de iniciativa de lideranças indígenas mulheres e implementado em 2015 pela ONU Mulheres Brasil em cooperação com a Embaixada da Noruega, que apresenta o objetivo de fortalecer a atuação de mulheres indígenas em espaços de decisão dentro e fora de suas comunidades e a elaboração de uma agenda que defenda as necessidades e interesses das mulheres indígenas em consonância com a diversidade entre os povos e de seus interesses comuns.

Pela primeira vez em 2016, apoiadas pela ONU, mulheres lideranças indígenas de diferentes etnias do Brasil, organizadas via Voz das Mulheres Indígenas, conquistaram espaço para tratar sobre as reivindicações e demandas das mulheres indígenas em plenária durante o $13^{\circ}$ Acampamento Terra Livre (ATL), evento que reuniu mais de 3 mil indígenas de todo o país em Brasília, promovido pela APIB, e do qual pude participar como ouvinte. Em plenária, foram apresentados vídeos de mulheres indígenas que, entre outras questões, tratavam sobre violência de gênero e formas de enfrentamento. Nas edições do mesmo evento em 2017 e 2018 a conquista do espaço na programação oficial por estas lideranças femininas se repetiu e se fortaleceu.

Grande parte das questões levantadas pelas mulheres indígenas durante o acampamento já estavam em debate durante a $1^{\circ}$ Conferência Livre de Saúde das Mulheres Indígenas, realizada em abril de 2017, em Brasília. Segundo Ângela Amanakwa Kaxuyana, participaram deste encontro mais de 36 mulheres indígenas representantes de diferentes etnias e estados. Ela afirma: "Foi um momento que a gente pôde socializar, discutir, ir lá, e apontar quais eram as nossas necessidades enquanto mulheres indígenas" (Kaxuyana, 2017).

A "Carta das Mulheres reunidas na $1^{\circ}$ Conferência Livre de Saúde das Mulheres Indígenas", publicada em 24 de abril de 2017, elenca nove tópicos relacionados a questões que afetam as vidas das mulheres indígenas, e as respectivas demandas, dentre as quais estão "Saúde mental e prevenção da violência contra as mulheres indígenas". Em relação a este tópico, a carta apresenta demandas como (CLSMI, 2017):

- Desenvolver estratégias de apoio às associações e coletivos de mulheres indígenas, que estejam trabalhando a conscientização e fortalecimento das mulheres, bem como ações de prevenção de situações de violências e conhecimento sobre a Lei Maria da Penha, quando for o caso.

- Garantir que seja realizada a notificação de todos os casos de violência contra as mulheres para que se conheça a dimensão deste problema e sejam desenvolvidas ações em saúde, tendo em vista que atualmente se identifica uma subnotificação destes casos.

- Orientar e capacitar as EMSI para a atenção às mulheres indígenas em situação de violência, considerando as especificidades dos diferentes povos.

Um dos objetivos desta primeira conferência, foi o de fortalecer a participação das mulheres indígenas no processo da $2^{\text {a }}$ Conferência Nacional de Saúde das Mulheres, realizada em agosto de 2017. Ângela Amanakwa Kaxuyana, membro do conselho de saúde, ressalta o aumento da participação das mulheres indígenas no evento:

Nessa conferência a participação da mulher indígena é um marco histórico, comparando com a primeira conferência que aconteceu há 30 atrás, onde, com certeza, as mulheres indígenas tiveram mais dificuldades de participar. Hoje está presente representantes de mais de 33 povos indígenas do país. É pouco diante do número existente, mas a gente está aqui em nome e na voz das mulheres indígenas de mais 330 povos existentes e a gente está em busca de realmente o reconhecimento do direito das mulheres indígenas na questão de atendimento à saúde, respeito, inclusão, e equidade principalmente no processo de discussão da política de saúde (Kaxuyana, 2017).

No que diz respeito às ações do Estado para garantia do amparo e proteção dos direitos das mul- 
heres indígenas, Valéria Paye Kaxuyana (Kaxuyana, \& Silva, 2008, p. 39) aponta que "o Estado brasileiro tem demonstrado ações ainda muito incipientes". Vale apontar, portanto, a importância das ações de lideranças indígenas na conquista destas políticas. A antropóloga Segato (2014) conta, por exemplo, que em 2002, as lideranças Rosane Kaingang e Miriam Terena solicitaram a Funai que oferecesse oficinas a mulheres indígenas de todas as regiões do Brasil, para que estas obtivessem um vocabulário com conceitos da teoria de gênero, e uma instrução sobre direitos humanos, direito dos povos indígenas e direito das mulheres indígenas. Esta oficina teve como produto uma cartilha apresentando reivindicações o que permitiu angariar fundos frente ao Ministério de Planejamento que propiciou a continuidade do trabalho através da realização de reuniões regionais com mulheres indígenas, culminando, em 2007, na criação, dentro da Funai da Coordenação de Gênero e Assuntos Geracionais, atual Coordenação de Gênero Assuntos Geracionais e Mobilização Social.

O debate sobre a Lei Maria da Penha (Lei No 11.340), ratificada em 2006, também se mostra central neste contexto. Fonseca (2015) aponta como as mulheres indígenas denunciam que o processo de construção desta lei não envolveu a participação efetiva das mulheres indígenas. Devido a esta invisibilização e à pressão das organizações, após a criação da Lei, ainda em 2006, realizou-se em Brasília um Encontro Nacional de Mulheres Indígenas com a participação de 28 mulheres de todas as regiões do Brasil para se discutir a lei (Segato, 2014). Já entre 2008 e 2010, foram realizados 13 Seminários Regionais Participativos e um outro Encontro Nacional envolvendo 457 mulheres indígenas representantes de 139 etnias, com o objetivo de estabelecer um diálogo sobre como enfrentar a violência doméstica ocorrida em contextos intra-étnicos. Os relatórios destes encontros, analisados por Fonseca (2015), apontam que durante o processo surgiram demandas como: "acolhimento psicológico das vítimas de violência e de agressores; capacitação de integrantes dos órgãos públicos que atuam junto aos povos indígenas quanto à questão da violência contra a mulher; criação de Casas de apoio às mulheres vítimas de violência; Inclusão do tema nas escolas, entre outros". Por outro lado, grupos de mulheres indígenas negaram a necessidade da apli- cação de uma lei estatal que interferisse nos seus regimentos internos e afirmaram a inexistência de violência de gênero em suas comunidades.

Nota-se que as reações apresentadas pelas mulheres de diferentes etnias e contextos territoriais a promulgação da lei e aos debates posteriores foram muito diversas. Samantha Ro'otsinana de Carvalho Juruna $^{12}$ e Valéria Paye Kaxuyana ) apontam, entretanto, que ainda há uma ausência de informação sobre a lei entre as mulheres indígenas e defendem a necessidade de divulgação da mesma. Para Ro'otsinana Juruna (Xavante, 2017), a tradução da Lei Maria da Penha nas diferentes línguas indígenas é uma boa iniciativa. Segundo ela "a partir do momento que a gente tem conhecimento de uma lei, a gente descobre que a violência que a gente sofre todo dia não é normal, é uma violência”. Entretanto, ela denuncia que os mecanismos de governo não estão preparados para receber estas denúncias e afirma que as mulheres que são lideranças devem buscar estratégias para dialogar sobre os direitos das mulheres indígenas em suas comunidades.

Para Valéria Kaxuyana (Kaxuyana, \& Silva, 2008), a Lei Maria da Penha deve ser considerada devido a introdução nas sociedades indígenas de valores machistas que prevalecem nas sociedades ocidentais:

O que se percebe é que os homens indígenas, interagindo em maior grau com a sociedade dita "dominante", têm sido fortemente impactados pelo machismo, que é um pano de fundo das relações de gênero nas sociedades ocidentais. A desestruturação das sociedades indígenas, de modo geral, tem incidido nos elos mais fracos dessa sociedade: as mulheres e as crianças. Portanto, se no passado a "lei dos brancos" não tinha muito a dizer para o universo indígena, hoje parece ser necessária (pp. 41- 42).

Em abril de 2018, as mulheres indígenas multiplicadoras do projeto Voz das Mulheres Indígenas distribuíram em Brasília, durante o ATL, uma cartilha que apresenta a "Pauta Nacional das Mulheres Indígenas" a partir de demandas apresentadas por mulheres de 104 etnias diferentes. Foi a primeira vez que se construiu um documento desta proporção. Dentre as

\footnotetext{
${ }^{12}$ Samantha Ro'otsinana Juruna é indígena xavante, liderança do movimento indígena nacional, protagonista do projeto Voz das Mulheres Indígenas, filha do ex-deputado Mário Juruna, e mestre em desenvolvimento sustentável pela Universidade de Brasília (UnB).
} 
pautas abordadas, além de demandas já recorrentes no movimento indígena e das pautas discutidas anteriormente, foram pontuados: "Igualdade de gênero (nas oportunidades de trabalho, nas comunidades, nas organizações indígenas, e nos cargos públicos)"; "Opressão de liberdade de expressão, por indígenas que impõe sua liderança na comunidade"; "Racismo/ Discriminação (nas cidades por não indígenas, principalmente nas escolas"; "Preconceito (dos homens na comunidade e pela sociedade na cidade)"; "Processos de formação e comunicação entre a base e as organizações/movimento de mulheres indígenas"; "Garantir a participação de mulheres indígenas em espaços decisórios das três esferas governamentais" e "Reconhecimento das lideranças mulheres, nos diálogos entre gerações".

Em um contexto mais amplo da América Latina, coletivos feministas dissidentes, denominados como pós-coloniais ou decoloniais, que não se identificam com os modelos e discursos realizados por feministas brancas - utilizam suas próprias experiências de exclusão, opressão e discriminação para desenvolver formas próprias de resistência e de trabalhar com os conceitos de gênero (Mayorga, \& Prado, 2010). A antropóloga afro-dominicana Ochy Curiel (2007) afirma que desde que surgiu o feminismo no contexto norte-americano, mulheres afrodescendentes, indígenas, chicanas, entre outras, ampliam esta perspectiva teórica e política apontando como essas mulheres têm sido racializadas e mais subalternizadas não só nas sociedades e nas ciências sociais, como também no próprio feminismo devido ao seu viés universalista e racista.

Com relação às mulheres indígenas, Curiel (2007) trata de um feminismo indígena incipiente na América Latina ${ }^{13}$ que, ao mesmo tempo que questiona as relações patriarcais racistas e sexistas das sociedades Latino Americanas, apontam críticas às suas próprias comunidades que mantém as mulheres subordinadas. Curiel afirma que " a pesar de que en los espacios académicos se representa a las mujeres indigenas solo como víctimas del patriarcado y la fuerza del capital, como actoras políticas han tenido posiciones poscoloniales críticas y radicales" (Curiel, 2007, p.100). Curiel cita Marta Sán- chez Néstor, feminista indígena amuga, intelectual e militante do movimento de mulheres no México e a nível internacional. Outros exemplos são Lorena Cabnal, indígena maya-xinka de Guatemala e Julieta Paredes, indígena aymara da Bolívia (Paredes, 2008). Ambas são militantes, intelectuais e escrevem sobre o feminismo comunitário proposto por Julieta Paredes.

\section{Considerações finais}

No contexto brasileiro, dada tamanha diversidade, os posicionamentos das mulheres dos movimentos indígenas são múltiplos, inclusive no que se refere a identificação com o feminismo. Apesar de algumas lideranças indígenas como RosimeryTeles, Valéria Paye Pereira Kaxuyana e Maria Gavião (2018) nomearem o movimento das mulheres indígenas como feminista, outras lideranças como Lindomar Terena (2017) criticam a atribuição desta categoria ocidental quando se trata das mulheres indígenas.

Torna-se, portanto, necessário buscar compreender as possibilidades múltiplas de narrativas, estratégias de lutas e realidades que termos como "movimentos de mulheres indígenas" e "organizações de mulheres indígenas" podem ocultar. In de pendente desta categorização, como vimos anteriormente, mulheres indígenas brasileiras estão falando sobre processos de desigualdade relacionadas ao menor prestígio das mulheres nas sociedades indígenas, a violência conjugal, a restrição das mulheres ao âmbito doméstico esvaziado de seu poder político, às violências que sofrem diante da sociedade não indígena, a invisibilização de suas pautas específicas e de seus movimentos de resistência, entre outros. Foram estas múltiplas vozes que nos fizeram iniciar uma reflexão sobre as possíveis aproximações e distanciamentos entre os movimentos de mulheres indígenas no Brasil e os feminismos pós-coloniais, e lançar a principal pergunta: o que há em comum?

Atentar-se para estas múltiplas narrativas e discursos se torna importante pois estas provocam tensionamentos múltiplos que envolvem, portanto, não só campos de disputa política por direitos e visibilidade, mas também campos teóricos da antropologia e do feminismo.

\footnotetext{
${ }^{13}$ Em seu livro, "Feminismos desde Abya Yala. Ideas y proposiciones de las mujeres de 607 pueblos en nuestra América” (2014), a escritora mexicana Celentani busca localizar e estudar as "rotas epistêmicas" de intelectuais indígenas feministas e "antifeministas" de diferentes países da América Latina, não se detendo, entretanto, no contexto brasileiro.
} 


\section{Referências}

Agier, M. (1991). Introdução. Caderno CRH, 4(Supl.), 5-16.

Arruda, R. S. V. (1994). Existem realmente índios no Brasil? Revista São Paulo em Perspectiva, 8(3), $77-85$.

Arruda, R. S. V. (2001). Imagens do índio: Signos da intolerância. In: C. A. Ricardo, Povos indígenas e a tolerância: Construindo práticas de respeito e solidariedade (pp. 43-63). São Paulo, SP: Universidade São Paulo.

Bento, M. A. S. (2007). Branquitude: O lado oculto do discurso sobre o negro. In: I. Carone, M.A.S. Bento (Orgs.), Psicologia social do racismo: Estudos sobre branquitude e branqueamento no Brasil (3a ed., pp. 147-162). Petropolis, RJ: Vozes.

Borda, O. F. (2009). Una sociología sentipensante para América Latina. Bogotá: Clacso. (era Fals Borda. O.)

Caldeira, V. A. (2001). História kaxixó: Aspectos etnográficos. Cadernos de História, 6(7), 74-83.

Caldeira, V.A. (2006). Caxixó: Um povo indígena feito de mistura (Dissertação de mestrado). Pontifícia Universidade Católica de São Paulo, São Paulo, SP.

Caldeira, V. A. (2008). Caxixó: O difícil reconhecimento de um povo indígena pelo estado brasileiro. Ariús: Revista de Ciências Humanas e Artes, 14, 29-39.

Castro, R., \& Mayorga, C. (2018). A construção de um campo de pesquisa antirracista ou sobre quando sujeito e objeto (se) pesquisam. Revista da $A B P N, 10(24), 339-365$.

Celentani, F. G. (2014). Feminismos desde Abya Yala: Ideas y proposiciones de las mujeres de 607 pueblos en nuestra América. Ciudad de México: Corte y Confección.

Centro de Documentação Eloy Ferreira da Silva - Cedefes. (2016). Plano de gestão territorial e ambiental na terra indígena Caxixó: Projeto BRA/13/019/FUNAI/CEDEFES. Belo Horizonte, MG: o autor. (era PGTATC)

Conferência Livre de Saúde das Mulheres Indígenas (2017). Carta das mulheres. Brasília, DF: Ministério da Saúde. Recuperado de http://conselho.saude.gov.br/ultimas_noticias/2017/doc/05mai22_mulheres_indigenas_carta_ final_IConferenciaLivre.pdf

Crenshaw, K. W. (2004). A intersecionalidade na discriminação de raça e gênero. In: Fundo de Desenvolvimento das Nações Unidas para a Mulher - Unifem, Cruzamento: Raça e gênero (pp. 7-19). Brasília, DF: o autor.

Curiel, O. (2007). Crítica poscolonial desde las prácticas políticas del feminismo antirracista. Nómadas, (26), 92-101.

Duarte, N. (2017). Minha vida como estudante no mundo dos brancos. Revista de Antropologia, 60(1), 35-46. https://doi.org/10.11606/2179-0892.ra.2017.132066

Figueiredo, K. (2016). Racismo: O instrumento disfarçado na negação de direitos: A luta dos indígenas da Terra Maró (PA). In: Anais da Reunião Brasileira de Antropologia: Ética, Diversidade e Conflitos. João Pessoa, PB, Brasil, 30.

Fonseca, L. D. (2015). A construção intercultural do direito das mulheres indígenas a uma vida sem violência: A experiência brasileira. Hendu, 6(1), 88-102. https://doi.org/10.18542/hendu.v6i1.2474

Gonçalves, B. S. (2015). Nem tupi nem tapuia: Livre determinação e polìticas sociais na trajetória histórica dos indígenas brasileiros. In: H. Martins, M. Garcia, M. Torres, \& D. Santos, Interseções em psicologia social: Raça/etnia, gênero, sexualidades (Coleção práticas sociais, políticas públicas e direitos humanos, pp. 32-54). Florianópolis, SC: Abrapso.

Grosfoguel, R. (2016). A estrutura do conhecimento nas universidades ocidentalizadas: Racismo/sexismo epistêmico e os quatro genocídios/epistemicídios ao longo do século XVI. Sociedade e Estado, 31(1), 25-49. https://doi. org/10.1590/S0102-69922016000100003

Guajajara S. (2018, abril). Povos indigenas, corpos e ideias para transformar a politica (Palestra). Belo Horizonte, MG: Universidade Federal de Minas Gerais. Recuperado de https://www.facebook.com/GuajajaraSonia/ videos/1789436047782709/

Guedes, M.. (2017, maio). Seminário: A liderança das mulheres indígenas (Curso de formação intercultural de educadores indígenas). Belo Horizonte, MG: Universidade Federal de Minas Gerais. Recuperado de https://www. youtube.com/watch?v=Ma8khw6GUe8\&feature=youtu.b

Haraway, D. (1995). Saberes localizados: A questão da ciência para o feminismo e o privilégio da perspectiva parcial. Cadernos Pagu, (5), 7-41. 
Kaxixó, A. (2017, maio). Conheça os índios Kaxixó. Jornal O Tempo, Entrevista. Recuperada de https:/ /www.otempo. com.br/tv/conhe\%C3\%A7a-os-\%C3\%ADndios-kaxix\%C3\%B3-1.1470133

Kaxuyana, A. (2017, set 15). Bate papo da Saúde - $2^{a}$ CNSMU: Mulheres indígenas e quilombolas. Canal Saúde Oficial. Entrevista. Recuperado de https://www.youtube.com/watch?v=nDZ5XPKVnC4 (era Amanakwa, A.)

Kaxuyana, V. P. P., \& Silva, S. E. S. (2008). A lei Maria da Penha e as mulheres indígenas. In: R. Verdum (Org.), Mulheres indígenas, direitos e políticas públicas. Brasília, DF: Instituto de Estudos Socioeconômicos.

Kopenawa, D., \& Albert, B. (2015). A queda do céu: Palavras de um xamã yanomami (B. Perrone-Moisés, Trad.). São Paulo, SP: Companhia das Letras.

Lei $N^{o} 11.340$, de 7 de agosto de 2006. Cria mecanismos para coibir a violência doméstica e familiar contra a mulher, nos termos do $\$ 80$ do art. 226 da Constituição Federal, da Convenção sobre a Eliminação de Todas as Formas de Discriminação contra as Mulheres e da Convenção Interamericana para Prevenir, Punir e Erradicar a Violência contra a Mulher; dispõe sobre a criação dos Juizados de Violência Doméstica e Familiar contra a Mulher; altera o Código de Processo Penal, o Código Penal e a Lei de Execução Penal; e dá outras providências. Diário Oficial da União. 8 ago 2006.

López, L. C. (2015). O corpo colonial e as políticas e poéticas da diáspora para compreender as mobilizações afro-latino-americanas. Horizontes Antropológicos, 21(43), 301-330. https:// doi.org/10.1590/S0104-71832015000100012

Luciano, G. S. (2006). O índio brasileiro: O que você precisa saber sobre os povos indígenas no Brasil de hoje. Brasília, DF: Ministério da Educação.

Lugones, M. (2007). Heterosexualism and the colonial/modern gender system. Hypatia, 22(1) 186-219.

Lugones, M. (2014). Rumo a um feminismo descolonial. Estudos Feministas, 22(3), 935-952. https://doi. org $/ 10.1590 / \% 25 x$

Mata, L.G. (2016). Memória do sagrado enquanto resistência ao medo. In: Conselho Regional de Psicologia de São Paulo - CRP-SP (Org.), Povos indígenas e psicologia: A procura do bem viver (pp. 79-83). São Paulo, SP: o autor.

Matos, M. H. (2012). Mulheres no movimento indígena: Do espaço de complementariedade ao lugar da especificidade. In: A. Sacchi, \& M. M. Gramkow (Orgs.), Gênero e povos indígenas (pp. 140-171). Rio de Janeiro, RJ: Museu do Índio.

Mayorga, C., Coura, A., Miralles, N., \& Cunha, V. M. (2013). As críticas ao gênero e a pluralização do feminismo: Colonialismo, racismo e política heterossexual. Revista Estudos Feministas, 21(2), 463-484. https://doi.org/10.1590/ S0104-026X2013000200003

Mayorga, C., \& Prado, M. A. M. (2010). Democracia, instituição e articulação de categorias sociais. In: C. Mayorga (Org.), Universidade cindida: Universidade em conexão ensaios sobre democratização da universidade (pp. 46-70). Belo Horizonte, MG: Universidade Federal de Minas Gerais.

Mayorga, C., Ziller, J., Magalhaes, M., \& Silva, S. (2010). O problema que não tem nome: metodologia para o estudo das desigualdades. In: C. Mayorga (Org.), Universidade cindida: Universidade em conexão? Ensaios sobre democratização da universidade (pp. 151-180). Belo Horizonte, MG: Universidade Federal de Minas Gerais.

Montero, M. (2004). Introducción a la psicología comunitaria: Desarrollo, conceptos y procesos. Buenos Aires: Paidós.

Oliveira, J. P. (2003). Os Caxixó do Capão do Zezinho: Uma comunidade indígena distante das imagens da primitividade e do índio genérico. In: A. F. M. Santos, \& J. P. Oliveira (Orgs.), Reconhecimento étnico em exame: Dois estudos sobre os Caxixó (pp. 141-201). Rio de Janeiro, RJ: Contra Capa.

Paredes, J. (2008). Hilando fino desde el feminismo comunitario. La Paz: Centro de Defensa de la Cultura.

Patai, D. (2010). História oral, feminismo e política. São Paulo, SP: Letra e Voz.

Quijano, A. (2000). Colonialidad del poder y clasificación social. Journal of World-Systems Research, 6(2), 342-386.

Rodrigues, M. (2015). Notas etnográficas sobre a ação política entre os Katxuyana (Monografia de graduação). Universidade Federal Fluminense, Niterói, RJ.

Sacchi, A. (2003). Mulheres indígenas e participação política: A discussão de gênero nas organizações de mulheres indígenas. Revista Anthropológicas, 14(1-2), 95-110. 
Santos, A. F. (2003). "A história tá é ali”: Sítios arqueológicos e etnicidade. In: A. F. M. Santos, \& J. P. Oliveira (Orgs.), Reconhecimento étnico em exame: Dois estudos sobre os Caxixó. Rio de Janeiro, RJ: Contra Capa.

Schucmam, L. V., Costa, E. S., \& Cardoso, L. (2012). Quando a identidade racial do pesquisador deve ser considerada: Paridade e assimetria racial. Revista da $A B P N, 4(8), 15-29$.

Segato, R. L. (2014). El sexo y la norma: Frente estatal, patriarcado, desposesión, colonidad. Revista Estudos Feministas, 22(2), p. 593-616. https://doi.org/10.1590/S0104-026X2014000200012

Spink, P. K. (2003). Pesquisa de campo em psicologia social: Uma perspectiva pós-construcionista. Psicologia \& Sociedade, 15(2), 18-42.

Terena, L. (2017). Feminismo indígena existe? Conheça as lutas da mulher indígena. São Leopoldo, SP: Centro de Estudos Biblicos. Recuperado de https://cebi.org.br/noticias/feminismo-indigena/

Teles, R., Kaxuyana, V. P. P., \& Gavião, M. (2018). Feminismo para as mulheres indígenas. Recife, PE: SOS Corpo - Instituto Feminista para a Democracia. Recuperado de http://soscorpo.org/feminismo-para-as-mulheres-indigenas/

Verdum, R. (2008). Mulheres indígenas, direitos e políticas públicas. Brasília, DF: Instituto de Estudos Socioeconômicos.

Voz das Mulheres Indígenas. (2018). Pauta nacional das mulheres indígenas (Cartilha). Brasília, DF: ONU Mulheres Brasil. Recuperado de http://www.onumulheres.org.br/wp-content/uploads/2018/06/PAUTA-Mulheres-indigenas-1.pdf

Xakriabá, Célia C.. (2018, mar 29). Célia Xakriabá defende produção acadêmica indígena. Entrevista.UnBTV. Recuperado de https://www.youtube.com/watch?v=gdlEP0v0CW8

Xavante, R. J. (2017, maio). Seminário: A liderança das mulheres indígenas (Curso de formação intercultural de educadores indígenas). Belo Horizonte, MG: Universidade Federal de Minas Gerais. Recuperado de https://www. youtube.com/watch?v=Ma8khw6GUe8\&feature=youtu.b

\section{Juliana Cabral de O. Dutra}

Mestranda do Programa de Pós-Graduação em Psicologia da Universidade Federal de Minas Gerais (UFMG), Belo Horizonte - MG. Brasil. Graduada em Ciências Socioambientais pela UFMG com formação complementar em Geografia pela Universidade Federal do Amazonas (UFAM), Manaus - AM, Brasil.

E-mail: julianasocioambientais@gmail.com

(iD) https://orcid.org/0000-0001-9439-3236

\section{Claudia Mayorga}

Professora do Departamento de Psicologia e do Programa de Pós-graduação em Psicologia da Universidade Federal de Minas Gerais (UFMG), Belo Horizonte - MG. Brasil. Doutora em Psicologia Social pela Universidade Complutense de Madri, Madrid, Espanha.

E-mail: claudiamayorga@ufmg.br

(iD) https://orcid.org/0000-0003-1728-0726

Endereço para envio de correspondência:

Fundação Nacional do Índio, Travessa Pedro Lemos, n 1003, B, Bairro Centro, Altamira / PA. CEP 68.371-060

Recebido 24/03/2019

Aceito 06/05/2019

Received 03/24/2019

Approved 05/06/2019

Recibido 24/03/2019

Aceptado 06/05/2019 
Dutra, J. C. O., \& Mayorga, C.(2019). Mulheres indígenas em movimento.

Como citar: Dutra, J. C. O., \& Mayorga, C.(2019). Mulheres indígenas em movimentos: Possíveis articulações entre gênero e política. Psicologia: Ciência e Profissão, 39(n.spe)., 113-129. https://doi.org/10.1590/1982-3703003221693

How to cite: Dutra, J. C. O., \& Mayorga, C.(2019). Indigenous women in movements: Possible links between gender and politics. Psicologia: Ciência e Profissão, 39(n.spe)., 113-129. https://doi.org/10.1590/1982-3703003221693

Cómo citar: Dutra, J. C. O., \& Mayorga, C.(2019). Mujeres indígenas en movimientos: Posibles articulaciones entre género y política. Psicologia: Ciência e Profissão, 39(n.spe)., 113-129. https://doi.org/10.1590/1982-3703003221693 